\title{
Intervenção educacional no processo de organização sociocomunitária em populações atingidas por barragens
}

\begin{abstract}
RESUMO: Este estudo teve como objetivo avaliar a contribuição que o processo educacional trouxe para a organização sociocomunitária dos reassentados do Núcleo Fazenda Nova, um dos 15 criados para abrigar as famílias que tiveram suas terras inundadas com a formação do lago, decorrente da construção da Barragem Pedra do Cavalo, na região fumageira do Recôncavo Baiano. Possui uma abordagem qualitativa do tipo Estudo de Caso, utilizando, como técnicas de coleta de dados, a entrevista semiestruturada e o grupo focal. Para complementar as informações, utilizou-se também a análise documental. Os sujeitos do estudo foram 37 pessoas, distribuídas de acordo com a sua representação e a análise dos dados foi orientada pela técnica de Análise de Conteúdo. Os resultados revelaram que a intervenção educacional, realizada pelas instituições governamentais, não proporcionou aos reassentados a conquista da autonomia, gerando forte dependência ao poder instituído. A participação dos reassentados, em prol de melhores condições de vida, por meio da organização sociocomunitária, ainda não foi conquistada.
\end{abstract}

PALAVRAS-CHAVE: Intervenção pedagógica. Participação da Comunidade. Organização da comunidade.

\section{Introdução}

O modelo de geração de energia, intensificado no Brasil durante a década de 70 do século passado, contemplava a geração de energia, a partir de grandes barragens. Dessa forma, Usinas Hidrelétricas (UHE) foram construídas, em todo o país, com o objetivo principal de gerar eletricidade para as indústrias eletrointensivas, como forma de promover o desenvolvimento da economia nacional. (MAB, 2003)

A Barragem Pedra do Cavalo, na região fumageira do Recôncavo baiano, foi mais uma construção em que os impactos sociais dessa lógica desenvolvimentista não consideraram a população atingida que depende da terra para sua sobrevivência.

O estudo, aqui apresentado, foi realizado no Núcleo Fazenda Nova, situado no município de Rafael Jambeiro, Bahia. O núcleo é um dos 15 criados para abrigar as famílias que tiveram suas terras ocupadas, com a formação do lago, decorrente da construção da Barragem Pedra do Cavalo. A pesquisa teve como objetivo avaliar a contribuição que o processo educacional, realizado durante a intervenção institucional, trouxe para a organização sociocomunitária do Núcleo Fazenda Nova.

\section{Edinaldo Medeiros Carmo} Professor da Universidade Estadual do Sudoeste da Bahia, UESB, Brasil. medeirosed@ig.com.br 
Os reassentados do núcleo viviam nos municípios de Antônio Cardoso e Santo Estevão, interior da Bahia, na faixa ribeirinha do Paraguaçu, numa região de chuvas mais frequentes e de um solo bastante fértil. Residiam em suas próprias terras, delas tiravam o sustento e ainda usufruíam da água do rio para consumo humano, dos animais e da pesca. Atualmente, moram numa área de poucas chuvas, solos pobres e com baixíssima oferta de água.

Além destas, existem significativas diferenças culturais entre as populações ribeirinhas e as sertanejas do semiárido, o que faz da realidade do núcleo um contexto ainda mais complexo. As comunidades ribeirinhas estão adaptadas a um meio abundante de recursos, enquanto que as sertanejas têm sua história marcada pela escassez e por precárias condições de vida. Contudo, ambas, dentro de suas próprias realidades, vão construindo formas bem características que garantem sua sobrevivência. Quando uma destas populações é afastada de seu local de origem, além da "perda" de identidade cultural, precisa encontrar outras formas de driblar as condições impostas pelo novo contexto como é o caso do Núcleo Fazenda Nova.

Outro aspecto a ser considerado é que a implantação do referido núcleo foi institucional, ou seja, é um assentamento artificialmente formado, o que faz com que aquelas pessoas não se sintam pertencentes àquele contexto, dificultando a formação de uma identidade comunitária.

Dessa forma, questionamos: até que ponto o processo de fragmentação sociocomunitária e espacial influenciou na descaracterização de valores sociais e culturais dos sujeitos, dificultando, pela fragilidade de sentimento de pertença com o local, a organização comunitária característica da dinâmica dos movimentos sociais? De que forma o processo educacional, realizado com a intervenção institucional, possibilitou aos reassentados a construção de um contexto comunitário politicamente organizado e socialmente sustentável?

Considerando as questões de pesquisa e os objetivos traçados, optamos por uma abordagem qualitativa do tipo Estudo de Caso, por acreditar que as representações, os conflitos, os determinantes históricos, culturais, políticos e sociais não seguem graus de linearidade, mas aparecem inter-relacionados e caracterizados pelas especificidades dos diferentes contextos. 
Utilizamos, como técnica de coleta de dados, a entrevista semiestruturada e o grupo focal. A fim de compreender melhor o contexto e complementar as informações, utilizamos também a análise documental. Os sujeitos do estudo foram 37 pessoas, distribuídas em quatro grupos de representação: grupo I (informantes-chave - ex-funcionários da empresa responsável pelo reassentamento e representantes do movimento de resistência); grupo II (lideranças locais); grupo III (moradores do núcleo); e, ainda, outros moradores que participaram de grupos focais, constituindo o grupo IV (jovens, adultos, idosos). A análise dos dados foi orientada pela técnica de Análise de Conteúdo, na qual, por meio da identificação dos núcleos de sentido encontrados nos conteúdos das entrevistas, foram definidas as categorias de análise.

Nas análises e discussões dos dados, procuramos articular os vários olhares, trazendo depoimentos dos diferentes sujeitos sociais, nas estruturas convergentes e/ou divergentes, a fim de construirmos uma discussão crítico-reflexiva, na qual o diferente também fosse contemplado para enriquecer o conteúdo, mediante as distintas formas de apreender a realidade.

Por último, fundamentamos as falas, trazendo os teóricos que sustentam e dialogam com os dados empíricos, num processo de triangulação. Esse caminho percorrido permitiu chegar à categoria de análise que apresentamos a seguir.

\section{Participação: conflitos nas intervenções socioeducacionais}

Os dados obtidos por meio das entrevistas com os reassentados, evidenciaram que as famílias do Núcleo Fazenda Nova não possuíam história de luta e organização comunitária anterior ao reassentamento, fato que marca a forma como esses sujeitos se comportaram ao longo desses anos. Diante das muitas perdas e poucas conquistas, raras vezes a comunidade conseguiu agrupar-se para decidir, coletivamente, sobre questões de interesse comunitário e fazer mobilizações, em função das promessas governamentais não cumpridas. A falta de uma experiência anterior, com processos organizativos, imobilizou aquelas pessoas.

$\mathrm{Na}$ verdade, parece muito exigir ações coletivas de uma comunidade que fora constituída pelo critério de fragilidade organizacional e vulnerabilidade social. De forma intencional, a 
população escolhida pela empresa responsável pelo reassentamento foi constituída de idosos e pessoas que não tinham, no seu passado, qualquer envolvimento com organização comunitária, pois o convencimento, por meio de promessas, seria muito mais fácil e foi essa a manobra de convalidação, utilizada pela empresa, para fazer valer os seus interesses.

Considerar esse aspecto é extremamente significativo para compreendermos a imobilidade dos reassentados, ao longo desses anos. A participação política não era uma prática comum entre aquelas pessoas. Além do mais, muitos deles nem se conheciam, muito menos possuíam um projeto social comum.

Outro aspecto a ser destacado é que as atividades, na tentativa de organização social, desenvolvida pelas instituições ligadas ao governo do Estado, tinham um cunho puramente assistencialista, no qual se configurou uma forte relação de dependência. Como quase sempre acontece, um técnico vai aos espaços de reassentamento, observa, faz um diagnóstico e traz os 'pacotes' prontos para serem executados, às vezes, distantes da realidade, sem considerar o saber popular e as vivências anteriores das pessoas. A comunidade não participou dos processos de planejamento, apenas foi convidada para executar ações pensadas pelos técnicos.

Ferreira (1985 apud Peruzzo, 2004), quando se refere ao envolvimento da comunidade em programas públicos, destaca os níveis de participação: nas decisões, na execução e nos resultados. Relacionando a classificação apresentada com o contexto que analisamos, percebe-se que o nível de participação dos reassentados, durante as atividades propostas pelos órgãos institucionais, limitava-se à execução de ações, previamente definidas. Em visitas ao núcleo, representantes governamentais e da empresa reuniam a comunidade, às vezes um pequeno grupo, realizavam diagnósticos e pensavam algumas atividades de intervenção na área social (tentativa de organização comunitária, acesso aos serviços de saúde, etc.) e na adaptação com as novas condições de trabalho (capacitação para o uso devido do solo, introdução de outras culturas agrícolas, etc.). No entanto, restringiram-se a ações pontuais, logo depois do reassentamento, nos quais, processos educativos para a emancipação e autonomia não foram instituídos. Assim, foram estabelecidas relações de participação, controladas por meio de consultas e da colabo- 
ração de alguns membros da comunidade, caracterizando-se numa relação paternalista e assistencial, visando 'camuflar' o descaso que vivia a população atingida.

Baquero (2003), ao discutir a contribuição do capital social na estruturação de uma cultura política participativa, no Brasil, destaca que, em contextos em que as pessoas não têm poder, estas são facilmente convencidas por promessas populistas ou, simplesmente, caem numa passividade permanente.

Analisando o contexto do estudo, os aspectos apontados são aproximações explicativas para a inércia organizacional, observada na história de 20 anos de reassentamento dos moradores do Núcleo Fazenda Nova. A ausência de poder ou contrapoder gerou uma forte relação de dependência ao governo do Estado, representado pela Companhia de Desenvolvimento do Vale do Paraguaçu (Desenvale) e pela Companhia de Desenvolvimento e Ação Regional (CAR), posteriormente. As promessas, advindas facilmente, eram acatadas e o não cumprimento destas não gerou mobilizações coletivas em prol de melhores condições e qualidade de vida. A passividade fez parte da história dessas famílias. A participação concedida foi, apenas, uma forma de convalidar as decisões definidas pelos técnicos. Sobre esse aspecto, SchererWarren (2001) considera que a participação nas políticas públicas guarda múltiplas possibilidades, porém, faz-se necessário cuidar para que a participação não seja, apenas, para legitimar a vontade do poder instituído.

Demo (2001a) ressalta que, em situações de pobreza material, mas, principalmente, pobreza política, não se pode esperar que as pessoas participem adequadamente, sem que antes tenham conquistado seu processo de autonomia.

De acordo com Díaz Bordenave (1987), a participação não deve ser apenas um instrumento para a solução dos problemas, mas uma necessidade fundamental do ser humano, uma tendência inata de realizar-se e afirmar-se a si mesmo, envolvendo a interação com os demais homens, a autoexpressão, o desenvolvimento do pensamento reflexivo e, ainda, a valorização de si mesmo pelos outros. Por isso, destaca que a participação possui duas bases que se complementam: uma afetiva e outra instrumental.

Entretanto, contrária a essa concepção de participação, a prática desenvolvida, institucionalmente pelos órgãos governamentais aumentou, ainda mais, a relação de dependência dos 
reassentados, tornando-os inabilitados para gerirem o destino do núcleo, na ausência da assistência institucional. Lideranças não foram formadas, ou melhor, os cursos nem sequer serviram para instrumentalizar as lideranças, processos participativos não foram verdadeiramente vivenciados. A associação de moradores foi criada alguns anos mais tarde, mas as pessoas não foram preparadas para assumir o comando, ou ainda, as pessoas não foram sensibilizadas para pensar um projeto social, coletivamente. A associação foi, também, uma estratégia pensada por alguém externo ao núcleo. Não defendemos que isso não possa acontecer, mas questionamos quando a comunidade não participa do processo. Demo (2001b), ao falar de planejamento participativo, aborda esta questão, afirmando que ela pode acontecer, desde que se busque convencer a comunidade da necessidade de determinada ação por meio de um espaço conquistado de participação, tomando por base, os interesses da comunidade, considerando sua contribuição e sua potencialidade.

Nesta perspectiva, o associativismo civil é uma das formas de organização formal de ações coletivas criadas pelos sujeitos sociais, mediante a identificação e propostas comuns, levantadas perante as demandas comunitárias. (SCHERER-WARREN, 2001)

Demo (2001a, p. 173), ao retratar a participação na avaliação de projetos de intervenção e ação, destaca um tipo de estratégia para a competência política presente na Comuna de Paris, "[...] o da força dos grupos pequenos bem organizados como requisito anterior à organização maior posterior", e critica as associações em que são fundadas, registrados seus estatutos, que só depois vão atrás dos associados. Por último, destaca que "o poder associativo está na base e jamais dela pode ser retirado". (DEMO, 2001a, p. 174)

Contudo, a associação do Núcleo Fazenda Nova foi criada num mecanismo do topo para a base. Os reassentados não foram ouvidos durante as intervenções institucionais realizadas, a comunidade não aprendeu (saber instrumental) a gerir os bens comunitários por meio da associação. Isso fez com que a associação fosse parar nas mãos de pessoas externas à comunidade, com interesses eleitorais. Consequentemente, os assentados não sabem o que é a associação, nunca conseguiram compreender sua importância e função, além de não se sentirem capazes de assumi-la e geri-la. 
Krishna (2002 apud BAQUERO, 2003) defende que não basta a existência de instituições democráticas, criadas de cima para baixo, para garantirem a estabilidade política e a justiça social. De acordo com os depoimentos, percebemos que não foram os reassentados que procuraram alguém para auxiliar na constituição de uma associação, o movimento deu-se de maneira inversa: na época, um candidato a vereador foi à comunidade para tentar 'organizá-los' por meio de uma associação.

Segundo Peruzzo (2004), manipular a comunidade pode ser uma tentativa de adequar suas necessidades aos interesses de quem detém o poder, usando o grupo social para obter popularidade e legitimação política, com vistas a resultados eleitorais favoráveis. Nas palavras de Demo (2001b), quando afirma que participação não pode ser concedida, não é uma dádiva, é conquista, encontramos elementos que talvez possam justificar, também, porque os moradores não deflagraram um processo de participação política, nesse momento.

É possível notar, ainda, que a ausência de organização interna pelos reassentados, fruto da emancipação política, possibilitou a sua subordinação a candidatos, em troca de favores do Estado que, por direito, deveriam estar disponíveis. A prática clientelista, em que o político se apropria dos recursos públicos para serem eleitos, está fortemente presente nas comunidades que ainda não tomaram consciência do processo no qual estão inseridos para expressar poder.

Um aspecto, a ser ressaltado, é que o processo comunicativo, utilizado por pessoas externas ao núcleo, muitas vezes, não conseguia deflagrar a autonomização dos reassentados; os argumentos trazidos, talvez a linguagem, não contribuíram para que os sujeitos conseguissem entender o que realmente é uma associação, sua importância, sua função, os subsídios que ela pode dar para a comunidade, pois a informação levada não era compreendida e apreendida pelos moradores.

Freire (1992) enfatiza o processo ensino-aprendizagem, quando discute os conceitos de comunicação e extensão. Este último, segundo o autor, deve ser abandonado pelos educadores e destaca que, na comunicação, os sujeitos são ativos e quando cointencionados ao objeto de seu pensar, comunicam o seu conteúdo através de um sistema de códigos linguísticos, sendo imprescindível que a expressão verbal de um dos sujeitos seja 
percebida pelo outro dentro de um quadro significativo comum. Às vezes, a linguagem técnica, expressa num universo de signos linguísticos próprios, não favorece às pessoas a apreensão das informações em torno do significado. Freire (1992, p. 71) esclarece que: "Ou o signo tem o mesmo significado para os sujeitos que se comunicam, ou a comunicação se torna inviável entre ambos por falta de compreensão indispensável". Esta prática rompe a estrutura dialógica do conhecimento, tornando mera transmissão ou extensão sistemática do saber.

Alguns entrevistados, ao compararem o processo comunicativo com a educação formal, mesmo não sabendo ler e escrever, destacaram a importância de o mediador reportar-se às necessidades de aprendizagem do aprendiz, para que a apreensão do saber aconteça. Nos espaços ditos não-formais, a exemplo das associações, a aprendizagem dá-se por intermédio também da articulação e agregação de interesses e de valores. (BAQUERO, 2003) Inicialmente, geram-se hábitos de cooperação, solidariedade e espírito público, além do efeito educacional, uma vez que os participantes adquirem habilidade e competências indispensáveis para a democracia.

Outro aspecto percebido, por meio dos dados empíricos, foi que, mesmo possuindo pouco, às vezes nenhum domínio do código escrito, os entrevistados ressaltaram a importância de os filhos frequentarem a escola, destacando, principalmente, a necessidade de eles possuírem conhecimento formal. Ao afirmar que "[...] trabalho aqui apanhano fumo pra comprar um punhado de farinha, dar um caderno ao filho que vai estudar (sic)" (Grupo II, ent. 2), notamos que a educação aparece, no discurso, como uma de suas prioridades. Tal fato pode estar relacionado ao desejo de não querer que os seus filhos passem as mesmas dificuldades enfrentadas por eles pela falta de escolarização.

Outros depoentes ressaltaram que a falta de oferta de ensino para os filhos é uma das dificuldades enfrentadas no cotidiano dos reassentados. Esse aspecto é assim apontado porque, no núcleo, a oferta de escolarização é da pré-escola à quarta série do ensino fundamental. Para cursarem as séries seguintes, as crianças e jovens necessitam se deslocar, aproximadamente, $10 \mathrm{~km}$ para os distritos mais próximos. Vale destacar que a Secretaria Municipal de Educação tem disponibilizado transporte escolar para que os estudantes cheguem à escola. 
$\mathrm{Na}$ fala dos entrevistados, notamos também que, muitas vezes, os reassentados percebiam que o processo educacional, vivenciado nos espaços organizacionais, contribui para a formação da consciência política. Ao afirmar que "[...] as pessoas fica mais ativa, mais experiente, começa mais a conhecer as pessoa, conversar e talvez possa conseguir alguma coisa através da organização da comunidade (sic)" (Grupo II, ent. 3), o depoente expressa sua percepção para a importância desses espaços. Baltazar (2004), ao avaliar a relação entre a militância de lideranças populares com a vida cotidiana, salienta que existe uma grande valorização do conhecimento informal adquirido através da participação política nesses espaços, no entanto, os militantes ressaltaram a importância da realização da aprendizagem formal.

Cabe, ainda, algumas considerações sobre a intervenção educacional desenvolvida pelos órgãos institucionais. Nas situações educativas, o conhecimento do mundo é tomado como algo que deve ser transferido e depositado nos educandos. O conhecimento, entretanto, exige uma presença curiosa do sujeito, requer sua ação transformadora sobre a realidade. Por isso, no processo de aprendizagem, aprende, verdadeiramente, aquele que se apropria do aprendido e o transforma em apreendido, reiventando-o, sendo, assim, capaz de aplicar o aprendido-apreendido em situações concretas. Diferentemente, nos casos em que ocorre transferência de conhecimento, sem envolvimento do sujeito, com processos estáticos, verbalizado, desconsiderando o conhecimento popular em detrimento do saber técnico, a aprendizagem não acontece. (FREIRE, 1992)

Nesse estudo, analisando a trajetória dos reassentados, percebemos que, mesmo não possuindo uma história de luta comunitária anterior ao reassentamento, naquele novo espaço, as iniciativas institucionais não conseguiram mobilizar a comunidade para estabelecer espaços participativos.

Segundo Demo (2001b, p. 33), a iniciativa de organização da sociedade civil ainda é muito baixa e destaca que:

A consciência dos processos dominativos pode ser tão restrita e coibida, que a proposta de associação em defesa de interesses específicos aparece estranha, quando não tímida. Ao mesmo tempo, emerge aí a dificuldade de motivar processos participativos por falta de organização mínima. Sequer são sentidos como necessidade básica, até porque, em situação de 
pobreza sócio-econômica extrema, pensa-se mais na sobrevivência imediata, do que na necessidade de garanti-la como direito definitivo.

Analisando o contexto dos reassentados, à luz destas palavras, inferimos que as iniciativas de organização social talvez não tenham sido percebidas pela comunidade como estratégias de dominação, mas também, por outro lado, não conseguiram sensibilizá-los para a necessidade de resolver os problemas comunitários em espaços participativos, nem mesmo foram capazes de conscientizá-los, na prática, de que a participação não é, senão, uma expressão de poder coletivo. Díaz Bordenave (1987) destaca, dentre os aspectos que condicionam à participação, a relação de submissão que pode ser instituída. Tal fato pode gerar uma pseudoparticipação ou uma participação passiva, na qual o expectador consente, submete e delega poder a outrem.

\section{Considerações finais}

Considerando o processo de desenraizamento, por que passaram as famílias do Núcleo Fazenda Nova, e à luz de todas as ponderações aqui trazidas, agir, coletivamente, tem sido uma difícil tarefa para os reassentados. Tomamos como referência conceitual, para dar suporte à análise, a participação enquanto capacidade de percepção dos sujeitos para agir coletivamente, expressando, assim, poder, ainda que esse poder seja, apenas, a tomada de consciência do excluído (TASSARA, 2002), e a participação como outra forma de poder que se conquista e se instaura de uma forma processual e infindável. (DEMO, 2001b) Assim, os dados empíricos nos fizeram concluir que a comunidade Fazenda Nova ainda não conseguiu se apoderar, ou melhor, o direito de participar, politicamente, foi-lhe tirado. A pobreza material, somando-se à pobreza política e aos equívocos cometidos ao realizar as intervenções educacionais, impediu os reassentados, por meio da consciência do processo em que estão inseridos, de expressarem seu poder.

Acreditamos que, somente por meio da participação, a comunidade poderá exercer sua cidadania, levando em conta que "[...] a passagem da cidadania tutelada para a cidadania assistida não é suficiente, porque esta estabelece mais facilmente o beneficiário que o cidadão, refreando o processo emancipatório". 
(DEMO, 2001a, p. 164) Embora a política social seja importante para o combate à pobreza, ela não emancipa, destaca o autor.

No contexto analisado, constatamos que a comunidade não conquistou autonomia para intervir na condução de suas histórias. À sombra da assistência institucional, a participação foi oferecida, equivocadamente, como dádiva. Participavam do ponto de vista técnico, não do ponto de vista político. O poder de intervir nos seus destinos foi sempre outorgado a outrem, que, com o discurso de 'organizá-los', os tornava mais passivos e dependentes. De acordo com Demo (2001b), o impedimento deve ser ponto de partida da participação, assim como a desigualdade pode ser fonte de mudança, contudo, os indivíduos precisam se organizar, participativamente.

As justificativas para culpá-los pela não participação podem ser ouvidas no discurso oficial, desqualificando o saber popular, em detrimento do saber técnico, que põe, em segundo plano, o saber acumulado pela população ribeirinha, impondo outra concepção de mundo, de sociedade, de desenvolvimento, reforçando a ideia, já incorporada pelos reassentados, de que a escolarização é condição indispensável para participar.

Acreditamos que um processo educativo, desenvolvido nos espaços não-formais, poderá ser um forte contributo para a população assumir a condução de sua história, não que a educação seja a responsável em superar as mazelas do mundo, nem tampouco pelo seu surgimento (COOMBS, 1986), mas a educação pode ser decisiva na constituição do sujeito, capaz de conduzir a própria história (DEMO, 2001a), podendo ser um forte instrumento para a participação política.

\title{
Pedagogical intervention in the process of communitarian organization in populations affected by dams.
}

\begin{abstract}
This study had as a goal to evaluate the contribution that the educational process brought to the socio-communitarian organization of the resettled population of the Núcleo Fazenda Nova, one of the fifteen ones created to house the families that had their land flooded due to the formation of the lake decurrent from the building of the Pedra do Cavalo Dam in the tobacco region of the Reconcavo Baiano. It has a qualitative approach of the Case Study type, using as data collection techniques the semi-structured interview and the focus group. To complement the information, the documental analysis was also used. The subjects of the study were 37 people, distributed according to their representation and the data analysis was oriented by the Contents Analysis technique. The results revealed that the educational intervention done by the governmental institutions did not bring the resettled
\end{abstract}


population the achievement of autonomy, hence causing strong dependence on the established power. The participation of the resettled population in favor of better life conditions through the socio-communitarian organization has not been achieved yet.

KEYWORDS: Pedagogical intervention. Participation. Communitarian organization.

\section{Referências}

BALTAZAR, Bernadete. Os encontros e desencontros da militância e da vida cotidiana. Psicologia: Teoria e Pesquisa, v. 20, n. 2, p. 183-190, maio - ago. 2004. Disponível em: < http://www.scielo.com.br > Acesso em: 16 mar. 2006.

BAQUERO, Marcello. Construindo uma outra sociedade: o capital social na estruturação de uma cultura política participativa no Brasil. Revista de Sociologia Política, n. 21, p. 83-108, nov. 2003. Disponível em: <http://www.scielo.com.br> Acesso em: 16 mar. 2006.

COOMBS, Philip H. A crise mundial da educação. 2. ed. São Paulo: Perspectiva, 1986.

DEMO, Pedro. Participação e avaliação: projetos de intervenção e ação. In: SORRENTINO, Marcos (Coord.). Ambientalismo e participação na contemporaneidade. São Paulo: EDUC/FAPESP, $2001 \mathrm{a}$.

Participação é conquista. 5. ed. São Paulo: Cortez, 2001b.

DÍAZ BORDENAVE, Juan E. O que é participação. 5. ed. São Paulo: Brasiliense, 1987.

FREIRE, Paulo. Extensão ou comunicação? 10. ed. São Paulo: Paz e Terra, 1992.

MAB: uma história de lutas, desafios e conquistas. Cadernos de Estudo, Brasília, DF, n. 7, 2003.

PERUZZO, Cecilia Maria Krohling. Comunicação nos movimentos populares: a participação na construção da cidadania. 3. ed. Petrópolis, RJ: Vozes, 2004.

SCHERER-WARREN, Ilse. Movimentos sociais e participação. In: SORRENTINO, Marcos (Coord.). Ambientalismo e participação na contemporaneidade. São Paulo: EDUC/FAPESP, 2001.

TASSARA, Eda Terezinha de Oliveira. Avaliação de projetos sociais: uma alternativa de inclusão? São Paulo: julho de 2002. Palestra apresentada no curso de Avaliação de Projetos Sociais: construção de indicadores. Promovido pelo Lab-Social. 